University of St. Thomas, Minnesota

UST Research Online

Fall 9-2012

\title{
Use of precedent and antecedent information in strategic cost management
}

\author{
Ozer Asdemir \\ University of St. Thomas, Minnesota, oasdemir@stthomas.edu \\ Mark Anderson \\ University of Calgary, andem@ucalgary.ca \\ Arindam Tripathy \\ University of Washington - Tacoma Campus, tripathy@uw.edu
}

Follow this and additional works at: https://ir.stthomas.edu/ocbacctpub

Part of the Accounting Commons

This Paper is brought to you for free and open access by the Accounting at UST Research Online. It has been accepted for inclusion in Accounting Faculty Publications by an authorized administrator of UST Research Online. For more information, please contact asle4660@stthomas.edu. 


\title{
Use of precedent and antecedent information in strategic cost management
}

\author{
Mark Anderson ${ }^{\mathrm{a}}$, Ozer Asdemir ${ }^{\mathrm{b}, *}$, Arindam Tripathy $^{\mathrm{c}}$ \\ ${ }^{a}$ Haskayne School of Business, University of Calgary, Calgary, AB, Canada T2N 1 N4 \\ ${ }^{\mathrm{b}}$ Opus College of Business, University of St. Thomas, Saint Paul, MN 55105, USA \\ c Milgard School of Business, University of Washington-Tacoma, Tacoma, WA 98402, USA
}

\section{A R T I C L E I N F O}

\section{Article history:}

Received 13 May 2011

Accepted 27 August 2012

Available online $\mathrm{xxxx}$

\section{Keywords:}

Cost behavior

Strategic cost management

Sticky costs

Resource procurement

Flexible resources

Committed resources

\begin{abstract}
A B S T R A C T
Integral to strategic cost management is the choice of procuring flexible versus committed resources conditioned on demand uncertainty. Prior research shows that costs respond less to decreases than increases in sales activity when firms invest in committed resources. We analyze asymmetry in cost behavior to investigate how resource procurement decisions between flexible and committed resources are related to precedent and antecedent information about demand uncertainty. We find that the asymmetry of cost responsiveness increases with historical sales growth and with the firm's market-to-book ratio, and decreases with historical sales volatility. We find similar results for firm-specific deviations of sales growth, sales volatility and the market-to-book ratio from the industry averages. These results illustrate how managers might combine precedent and antecedent information in formulating a resource procurement plan as a means of strategic cost management.
\end{abstract}

(c) 2012 Elsevier Inc. All rights reserved.

\section{Introduction}

Managing costs by utilizing resources effectively is regarded as fundamental to success in today's competitive environment (Finney, Campbell, \& Powell, 2005; Hooley, Greenley, Cadogan, \& Fahy, 2005). Due to advances in telecommunications and other information technology (IT), recent years have seen significant expansion of firms' opportunities to employ flexible resources rather than committed resources to support firm activities. Services such as Amazon offer online retailers the opportunity to outsource the entire direct-to-customer distribution network. Efficiency gained from IT also permits outsourcing of dataintensive tasks for accounting and control, information management, and customer support. In addition, companies may obtain flexible resources through traditional avenues, such as renting assets rather than purchasing them or hiring temporary rather than permanent employees.

Using flexible resources enables agility in cost management, but agility is not free. Due to risk transfer and market contracting, there is a price premium for flexible resources and firms that rely on flexible resources face the risk of price changes. Agility achieved through outsourcing also risks control loss and potential quality impairment (Kaya \& Özer, 2009; Ren \& Zhang, 2009; Ren \& Zhou, 2008). Moreover, the pursuit of flexibility through outsourced contracts exposes firms to political costs, particularly in large public firms (Dunn,

\footnotetext{
* Corresponding author. Tel.: +1 651962 5436; fax: +1 6519625093.

E-mail addresses: mark.anderson@haskayne.ucalgary.ca (M. Anderson), oasdemir@stthomas.edu (O. Asdemir), tripathy@uw.edu (A. Tripathy).
}

Kohlbeck, \& Magilke, 2009; McGee, 2005). Investing in committed resources develops in-house capability and control that may lead to cost management advantages. On the other hand, investing in committed resources subjects the firm to costs of carrying underutilized resources when activity demand is low because of resource scaling and high transactions costs associated with acquiring or disposing of committed resources.

Previous studies have evaluated cost management through resource procurement, focusing on labor markets. These studies model managers' resource procurement decisions with respect to uncertainty about future demand (Pinker \& Larson, 2003; Rebitzer \& Taylor, 1991). Firms optimize over a combination of permanent and contingent labor resources. Some researchers, for example Daniel, Lohrke, Fornaciari, and Turner (2004), have highlighted the importance of additional research into management of excess resources to enhance performance. We broaden the focus to examine resources other than labor by looking at the variety of resources represented by selling, general and administrative (SG\&A) costs. The extension of contingent contracting to resources other than labor is natural. For example, a firm might negotiate a long-term property lease with fixed payments or a short-term lease with payments equal to a percentage of sales. The first contract ensures long-term access to a resource at a known cost. The second provides short-term access to a resource at a cost that varies with the actual level of sales. Demand uncertainty should motivate a consistent managerial approach to procurement of all SG\&A resources. Our objective is to empirically examine the relationship between variables that could inform managers on the distribution of past and future demand and the choice of commitment versus flexibility as evident in asymmetric SG\&A cost behavior. 
Selling, general and administrative (SG\&A) costs make up a large portion of firm expenses (Neelankavila \& Alaganar, 2003) and represent a myriad of marketing and advertising, selling, distribution, management, and customer support activities. Resources used include office, selling and distribution facilities, management, selling and support labor, and communication and information infrastructure. Because of the diverse combination of resources required to support SG\&A activities and the less well-defined relation between SG\&A costs and production, the costs of these activities can be more difficult to manage than costs generated in producing the goods or services that the organization sells. The SG\&A costs incurred for a period are the product of multiple disparate contracts including rent and lease agreements, temporary and permanent employment commitments, purchase orders and contracts for external services. These costs are not necessarily volume driven, but must be managed through a combination of contingent contracting for flexible resources and investment in committed resources in order to support the potential and realized level of sales activity. Our study focuses on the procurement of flexible versus committed resources to manage SG\&A costs. Specifically, we are interested in empirically capturing variation in the mix of flexible versus committed SG\&A resources with respect to precedent and antecedent information about demand uncertainty.

In contrast to the fixed and variable cost model traditionally used in managerial accounting, studies using the "sticky costs" model (Anderson, Banker, \& Janakiraman, 2003) recognize that managers must intervene to adjust the resources that support an activity when the activity demand increases or decreases. Asymmetric cost responsiveness or "cost stickiness" happens when managers decide to retain resource slack created by a drop in activity demand. According to the sticky costs model, managers who are optimistic about future sales growth prospects are more likely to retain SG\&A resources when the adjustment costs are high relative to the costs of carrying slack resources. Anderson, Banker, Huang, and Janakiraman (2007) observe that financial analysts treat an increase in SG\&A as bad news regardless of the direction of the change in sales. They find that an increase in SG\&A when revenue declines is on average good news that is undervalued by the market. Banker, Byzalov, Ciftci, and Mashruwala (2012) find that the asymmetry in cost responsiveness reverses if revenue also declined in the preceding year.

Investment in committed resources exposes companies to the costs of carrying underutilized resources when demand falls. Due to the trade-off between the higher unit cost of using flexible resources and the potential cost burden of carrying underutilized committed resources, a mismatch between demand uncertainty and resource procurement exposes the company to greater operating risk. While the sticky costs literature focuses on managers' ex post decisions to retain or remove slack resources in response to a realized change in sales demand, we consider how managers' ex ante resource procurement decisions affect asymmetric cost responsiveness. So, rather than placing emphasis on managers' expectations of growth prospects in relation to a decline in sales, we look at how managers use their experience and available information to plan and manage strategically for the future. Procurement focused on agility, favoring flexible resources, leads to less asymmetric cost responsiveness because the adjustment costs are low relative to the costs of carrying slack resources. Following the labor studies that model contingent contracting as a response to demand uncertainty, we link asymmetric cost responsiveness to precedent and antecedent variables that capture information about demand growth and volatility for the firm and its industry.

We use two variables to capture information about demand growth: historical sales growth and the market-to-book ratio of the firm. We use historical sales volatility as a measure of demand volatility. We expect the precedent variables, historical sales growth and sales volatility, to be important for their information value and because they represent the demand environment under which the decision-making and control systems of the firm evolved. We expect the antecedent variable, the market-to-book ratio to be informative for the procurement choice because it is a common indicator of future growth expectations and a management performance benchmark. If resource procurement does correspond to demand uncertainty, then a persistent-growth firm should adopt control mechanisms that favor committed resources. A high-volatility firm should select mechanisms favoring flexible resources. Our first set of tests examines the link between resource procurement and demand uncertainty by relating asymmetric cost responsiveness of SG\&A costs to these precedent and antecedent variables for a broad cross-section of firms.

Our second set of tests controls for industry effects. These tests are compelling for a number of reasons. First, firms within an industry have similar resource needs. Second, companies within an industry face similar demand uncertainty. Third, competition within an industry pushes companies to adopt similar cost management practices. Thus, we expect that companies within an industry will generally have similar demand characteristics and resource procurement profiles. However, companies may differ from their peers because they adopt production or marketing models that lead to either greater sales volatility or more persistent growth. The resulting demand differences may in turn lead to SG\&A resource procurement decisions that are tilted more toward either cost agility or resource-based capability.

For our empirical analysis, we estimate an empirical model that relates the change in SG\&A costs between two adjacent periods to the change in sales between the same periods. The model includes an indicator variable to distinguish between sales increases and sales decreases. Previous studies that use this model have found that SG\&A costs go down less with sales decreases than they go up with sales increases (Anderson et al., 2003; Subramaniam \& Weidenmier, 2003). They attribute this asymmetric cost responsiveness to high adjustment costs relative to carrying costs for slack resources. We consider strategic aspects of managerial decision making about the procurement of SG\&A resources (see discussion in DeRijcke, Faes, \& Vollering, 1985) by observing that a resource procurement plan that favors flexible resources would lead to lower adjustment costs relative to carrying costs and a plan that favors committed resources would lead to higher adjustment costs relative to carrying costs. Therefore, greater asymmetric cost responsiveness would be associated with resource procurement that emphasizes committed resources.

We find that asymmetric cost responsiveness increases with the historical sales growth of the firm and decreases with the historical sales volatility of the firm. These results support the argument that managers' resource procurement plans are developed over time in alignment with demand uncertainty experience and that cost management practices tend to become institutionalized. We find that the degree of cost asymmetry increases with the market-to-book ratio. This supports the hypothesis that firms develop in-house capability by investing in committed resources when the prospects for demand growth are higher. When we control for industry average levels of sales growth, sales volatility and the book-to-market ratio, we find that asymmetric cost responsiveness increases with the firm-specific deviations from the industry mean of sales growth and the marketto-book ratio and decreases with the firm-specific deviation from the industry mean of sales volatility. This indicates development of firm-specific resource procurement plans that coincide with firmspecific demand uncertainty relative to industry peers.

Our results contribute to the study of strategic cost management through resource procurement choices under demand uncertainty by providing empirical evidence connecting asymmetry in cost behavior to precedent and antecedent information about sales growth and volatility. We also add to the analysis of strategic cost management within industries by linking asymmetry in SG\&A cost behavior to firm-specific measures of demand uncertainty. In the next section we discuss our hypotheses. Section 3 describes our empirical tests, analysis, and results. Section 4 concludes the paper. 


\section{Information, resource procurement, and cost behavior}

A resource procurement plan affects operating risk because of the potential mismatch between demand uncertainty and cost behavior. A manager hiring full-time employees rather than part-time employees, or entering into a long-term lease rather than an annual lease, has purchased reliable long-term access to a resource. However, if demand declines, such commitment could impede the firm's profitability. A manager with high growth expectations would want to invest in the committed resource in order to realize the benefits from the acquired capability, but a manager facing more up and down variability in demand would prefer the flexible resource. We observe that whether a firm has a flexible procurement profile or a profile typified by long-term commitments would manifest itself in measurable cross-sectional differences in the behavior of SG\&A costs.

We distinguish between flexible and committed resources in terms of granularity, carrying or usage costs, and adjustment costs. By granularity, we mean the lot size for acquiring resources in terms of units of capacity for that resource. By carrying or usage costs, we mean the costs of sustaining or using a lot size of resource capacity once that capacity has been acquired. By adjustment costs, we mean the costs of acquiring or disposing of a lot size of resource capacity. Carrying or usage costs and adjustment costs of resources include both pecuniary costs and non-pecuniary costs such as a loss of control when resources are sourced externally. This description of costs is consistent with active management of costs that is described in the sticky costs model.

Contracts for flexible resources are more granular than contracts for committed resources and may be contingent on the demand for the resources based on the level of sales activity. Carrying or usage costs per unit of capacity for flexible resources are typically higher than carrying or usage costs per unit of capacity for committed resources but adjustment costs for adding or removing flexible resources are normally lower than adjustment costs for committed resources. For example, a company may contract externally for information technology (IT) support or it may develop the capability internally. The flexible IT resource may be acquired in lot sizes of $1 \mathrm{~h}$ of support time as needed. The adjustment costs of obtaining the flexible resource externally would include basic contracting costs and the carrying or usage costs of the flexible resource would equal the cost per hour of support acquired during a period. The committed IT resource may be acquired by hiring IT support staff in lot sizes of $40 \mathrm{~h}$ per week. The adjustment costs of obtaining the committed resource internally would include search and training costs for employees and set-up costs for leased or purchased equipment. The carrying or usage costs of the internal resource would include employee salary and lease or capital charges (depreciation and interest) for the equipment. The adjustment costs of reducing the committed resource may include severance pay and the costs of disposing of equipment through lease termination or sale. Other examples of using flexible versus committed resources include hiring temporary employees versus permanent employees, entering short-term rental agreements for facilities and equipment versus long-term leases or purchases, contracting with consultants versus internal experts for various services, outsourcing back-office activities versus developing internal support, using online sales services such as Amazon versus self-hosted selling, and using external logistics providers such as UPS versus managing shipping internally.

The selection of a procurement plan focusing either on cost agility or cost advantages from committed resources should reflect expectations for demand growth and risk. Our choice of conditioning variables focuses on information that would influence the formation of management's expectations and the institutional arrangements governing management's choice set. First, we expect the level of resource commitment to vary with the historical growth of the firm. In addition to its potential predictive value, a firm's sales growth history reinforces a compatible set of corporate culture, systems, and rules governing cost management. Persistent growth would reward managers' willingness to invest in capability, engendering systems, rules, and relationships that support commitment rather than flexibility. On the other hand, a firm that has experienced low growth or decline would develop controls where long-term commitments are highly scrutinized. This leads to our first hypothesis stated as follows:

H1. Asymmetric cost responsiveness increases in the magnitude and persistence of historical sales growth.

Resource commitments that lead to asymmetric cost responsiveness are likely to be long-term commitments. Banker, Huang, and Natarajan (2011) find that incentive compensation is more long term when SG\&A resource expenditures create higher future value and that new equity incentives lead to higher resource expenditure when such expenditure creates more long-term value. Therefore, a manager making such commitments would develop long-term expectations of sales. Capital market valuation provides an indication of investors' growth expectations and may be used to proxy for long-term sales growth expectations of managers. The ratio of market to book value indicates investors' expectations of future abnormal earnings relative to assets in place. It reflects both the magnitude and persistence of sales growth expectations. It is salient to management's resource procurement plan because it captures expectations over a long-term time horizon and portrays confidence in future growth. Committed resources accommodate sales growth because lower carrying or usage costs per unit of committed resources make the cost of supporting increases in sales activity lower than if flexible resources were used. Managers with higher sales growth expectations will bear the higher adjustment costs of investing in committed resources in order to take advantage of the lower carrying or usage costs. Because cost asymmetry is associated with a higher mix of committed to flexible resources, we expect a positive relation between asymmetric cost responsiveness and the market to book ratio. Hypothesis two captures this.

H2. The asymmetric cost responsiveness increases in the magnitude of the market-to-book ratio.

Managers facing high sales volatility at the firm or industry level would be less willing to commit to contracts that increase resource capability because such contracts would create a mismatch between demand fluctuations and cost behavior, increasing operating risk. To the extent that past volatility predicts future volatility, managers would react to historically volatile sales by building flexibility in the SG\&A components of the value chain. Moreover, a firm with historically volatile sales is likely to have controls in place that scrutinize and discourage commitment. Higher sales volatility favors flexible resources relative to committed resources because the lower adjustment costs offset the higher carrying or usage costs of flexible resources when sales levels are more volatile. We expect, therefore, to find a negative association between asymmetry cost responsiveness and historical sales volatility as stated in our third hypothesis.

H3. The asymmetric cost responsiveness decreases with historical sales volatility.

Our development of hypotheses H1, H2 and H3 is based on differences in demand uncertainty across a broad spectrum of firms. Strategy is often considered from an industry perspective with companies developing firm-specific approaches for competing with rivals in their own industries. Because firms within an industry have similar resource needs and share common expectations about demand uncertainty, competition drives them to similar approaches to cost management. In fact, research indicates mean reversion in key performance indicators for firms competing in an industry (Baber, Kim, \& Kumar, 1999; Fairfield, Ramnath, \& Yohn, 2009; Lev, 1969). However, a company may face different demand uncertainty from its competition within an industry. It may, for instance, sell innovative products whose sales are 
more volatile or it may focus on growth through expansion into new markets. Under our hypotheses, a firm that experiences and anticipates growth would invest in committed resources to take advantage of lower unit costs and greater control. A firm that develops innovative products with short product life cycles would favor flexible resources that give it cost agility. Hypothesis four, stated below, extends hypotheses one, two and three by controlling for industry average effects.

H4. Controlling for industry average effects, asymmetric cost responsiveness increases with deviations from the industry mean for sales growth and the market-to-book ratio, and decreases with deviation from the mean for sales volatility.

In the next section we describe our empirical model, sample selection, and discuss the results of our analysis.

\section{Data analysis and results}

\subsection{Sample}

Our sample consists of 79,177 firm-year observations spanning 30 years, 1980 to 2009, from the COMPUSTAT database. We deleted firm-years with missing sales revenue or SG\&A costs and excluded firm-years where SG\&A costs were greater than sales revenue (Anderson et al., 2003). For each firm-year $t$ we required sales revenue to be available from $t-1$ to $t-5$ to calculate historical sales growth and sales volatility. We also excluded firm years with missing share price or number of shares, and missing or negative book value.

The time $t$ historical sales growth (Historical Growth ${ }_{i t}$ ) is the average annual sales growth between years $t-5$ and $t-1$. The time $t$ market-to-book ratio $\left(\mathrm{MTB}_{i t}\right)$ is market value divided by book value of equity at the end of year $t-1$. The time $t$ historical sales volatility (Volatility $_{i t}$ ) is the standard deviation of sales revenue from $t-1$ to $t-5$, with sales revenue scaled by total assets. We form an industry average of each variable of interest for each two-digit SIC industry. Firms within two-digit SIC codes containing fewer than four members are classified as "Other."

Descriptive information is provided in panel A of Table 1 . The mean (median) annual sales revenue is $\$ 2,385$ million ( $\$ 263$ million). The mean (median) annual SG\&A costs is $\$ 4413$ million ( $\$ 503$ million). The mean (median) average sales growth over the past 5 years is $14.86 \%$ (10.81\%). The mean (median) sales volatility is $0.20(0.15)$. The mean (median) market-to-book ratio is 2.24 (1.62).

\subsection{Empirical model}

Our basic empirical model is,

$\log \left[\frac{\mathrm{SGA}_{i, t}}{\mathrm{SGA}_{i, t-1}}\right]=\beta_{0}+\beta_{1} \log \left[\frac{\text { Sales }_{i, t}}{\operatorname{Sales}_{i, t-1}}\right]+\beta_{2} \times D_{i, t} \times \log \left[\frac{\text { Sales }_{i, t}}{\text { Sales }_{i, t-1}}\right]+\varepsilon_{i, t}$,

Table 1

Descriptive statistics.

\begin{tabular}{|c|c|c|c|c|c|c|}
\hline \multicolumn{7}{|c|}{ Sample period 1980-2009 } \\
\hline & $N$ & Mean & $\begin{array}{l}\text { Standard } \\
\text { deviation }\end{array}$ & Median & $\begin{array}{l}\text { Lower } \\
\text { quartile }\end{array}$ & $\begin{array}{l}\text { Upper } \\
\text { quartile }\end{array}$ \\
\hline $\begin{array}{l}\text { Sales revenue } \\
\quad \text { (millions) }\end{array}$ & 79,177 & 2384.55 & $10,480.43$ & 263.06 & 69.93 & 1064.60 \\
\hline SG\&A costs (millions) & 79,177 & 440.83 & 1814.43 & 50.14 & 14.53 & 191.65 \\
\hline Historical growth (\%) & 79,177 & 14.86 & 19.86 & 10.81 & 3.68 & 20.46 \\
\hline Volatility & 79,177 & 0.20 & 0.20 & 0.15 & 0.07 & 0.26 \\
\hline MTB & 79,177 & 2.24 & 2.17 & 1.62 & 1.04 & 2.60 \\
\hline
\end{tabular}

Historical growth: The average of four annual sales growth observations from $t-5$ to $t-4, t-4$ to $t-3, t-3$ to $t-2$, and $t-2$ to $t-1$. Volatility: The standard deviation of sales revenue (divided by total assets) for the years $t-5$ to $t-1$. MTB: Market value at the end of yeart-1 divided by book value at end of year $t-1$. where $D_{i, t}$ equals 1 if sales decreased between $t-1$ and $t$, and zero otherwise (Anderson et al., 2003). The dummy variable $D_{i, t}$ captures the asymmetric responsiveness of SG\&A costs to sales. The coefficient $\beta_{1}$ represents the change in SG\&A costs in relation to the change in sales when sales increase between $t-1$ and $t$. The sum of the coefficients $\beta_{1}+\beta_{2}$ represents the change in SG\&A costs in relation to the change in sales when sales decrease between $t-1$ and $t$. If SG\&A costs do not fall as much when sales decrease as they rise when sales increase by an equivalent amount, then the sum of $\beta_{1}$ and $\beta_{2}$ would be less than $\beta_{1}$ alone. Therefore, assuming $\beta_{1}>0$, asymmetric cost responsiveness is represented by $\beta_{2}<0$.

To test hypotheses $\mathrm{H} 1, \mathrm{H} 2$ and $\mathrm{H} 3$, we examine the effect of each variable of interest on the asymmetric cost responsiveness by expanding the basic model to include a term where the variable of interest is allowed to interact with $D_{i, t}$ and the change in sales as follows.

$$
\begin{aligned}
\log \left[\frac{\mathrm{SGA}_{i, t}}{\mathrm{SGA}_{i, t-1}}\right]= & \beta_{0}+\beta_{1} \log \left[\frac{\text { Sales }_{i, t}}{\operatorname{Sales}_{i, t-1}}\right]+\beta_{2} \times D_{i, t} \times \log \left[\frac{\text { Sales }_{i, t}}{\operatorname{Sales}_{i, t-1}}\right] \\
& +\beta_{3} \times \operatorname{Growth}_{i, t-1} \times D_{i, t} \times \log \left[\frac{\operatorname{Sales}_{i, t}}{\operatorname{Sales}_{i, t-1}}\right] \\
& +\beta_{4} \times \text { Volatility }_{i, t-1} \times D_{i, t} \times \log \left[\frac{\text { Sales }_{i, t}}{\text { Sales }_{i, t-1}}\right]+\varepsilon_{i, t}
\end{aligned}
$$

Growth $_{\text {it }}$ is either average historical growth over the past 5 years or the expected growth proxied by the market-to-book ratio. We estimate the model separately with historical or expected growth and we estimate a version of the model that includes both growth variables. Under our model specification, $\beta_{3}$ or $\beta_{4}$ would be negative if the given variable increases the asymmetry in cost response and positive if the variable reduces the asymmetry in cost response. Based on our hypotheses, we expect $\beta_{3}$ to be negative and $\beta_{4}$ to be positive.

We estimate our empirical model using ordinary least squares. We adjust the standard errors for heteroskedasticity, serial, and crosssectional correlation using a two-way cluster at the firm and year level suggested by Petersen (2009) as the preferred method for estimating standard errors using panel data. We winsorize any variable for values in the highest or lowest $0.5 \%$ of the sample.

\subsection{Results}

Table 2 provides the results of estimating the basic model. The estimated coefficients of $\beta_{1}=0.6445(t=110.24)$ and $\beta_{2}=-0.1893$ $(t=-16.50)$ are similar to findings of prior studies (i.e. Anderson et al., 2003; Subramaniam \& Weidenmier, 2003), consistent with

Table 2

Asymmetric cost responsiveness

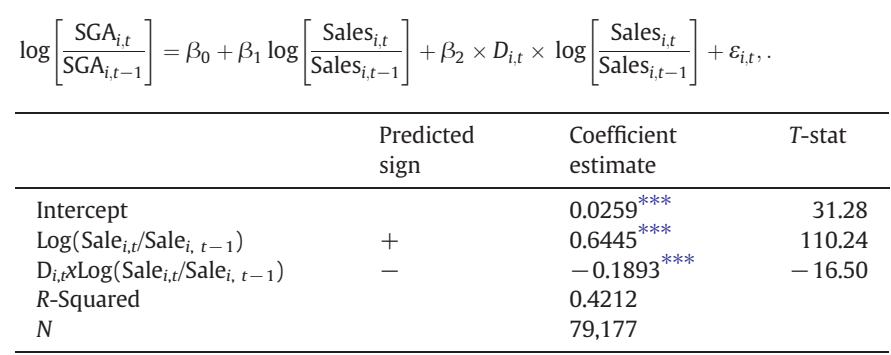

$t$-Statistics are calculated after adjusting the standard errors for heteroskedasticity, serial, and cross-sectional correlation using a two-way cluster at the firm and year level. $D_{i, t}$ : Dummy variable equals to 1 if Sales declined from $t-1$ to $t, 0$ otherwise. $* * * \quad p<0.01$. 
asymmetric cost responsiveness for sales decreases compared to sales increases.

We estimate the model with firm-level variables of interest to test our hypotheses $\mathrm{H} 1, \mathrm{H} 2$ and $\mathrm{H} 3$. The results, described below, are reported in Table 3. Column I reports the estimation results with the average historical sales growth and column II reports the estimation results with the market-to-book ratio as the Growth ${ }_{\text {it }}$ variable. Column III provides the estimation results with both growth variables included in the model. The condition index numbers when both historical growth and the market-to-book ratio are included is well below the suggested benchmark of 30 , indicating that multicollinearity is not a concern in our estimations (Belsley, Kuh, \& Welsch, 1980).

\subsubsection{Hypothesis HI: Historical sales growth}

Under hypothesis $\mathrm{H} 1$, asymmetric cost responsiveness would increase with average historical sales growth implying that the coefficient on the historical growth variable would be negative. The estimated coefficient $\beta_{3}$ for the historical sales growth term is -0.3736 $(t=-12.18)$ in column I and $-0.3318(t=-10.55)$ in column III, supporting hypothesis $\mathrm{H} 1$. The fact that growth history has an incremental effect to the market-to-book ratio in column III, and vice versa, is interesting because it indicates distinctive properties for each growth variable.

\subsubsection{Hypothesis H2: Market-to-book ratio}

The market-to-book ratio provides an indication of long-term sales growth expectations. Accordingly, our prediction under hypothesis $\mathrm{H} 2$ is a negative coefficient on the MTB variable. The estimated coefficients $\beta_{3}$ for the market-to-book ratio are $-0.0408(t=-12.07)$ in column II and $-0.0365(t=-10.66)$ in column III. This provides support for $\mathrm{H} 2$ and for interpretation of asymmetric cost responsiveness as an indication of the firm's long-term resource commitments.

\subsubsection{Hypothesis H3: Sales volatility}

Under hypothesis $\mathrm{H} 3$, historical sales volatility would be negatively associated with asymmetric cost responsiveness, meaning that the estimated coefficient for the volatility term in our model would be positive. The estimated coefficient $\beta_{4}$ is significantly positive in all of the columns of Table 3. Column I reports a coefficient of $0.2571(t=9.50)$, Column II reports a coefficient of $0.2573(t=10.48)$ and column III reports a coefficient of $0.2858(t=11.40)$. While our results for $\mathrm{H} 1$ and $\mathrm{H} 2$ indicate that past growth history and future growth prospects encourage commitment, our results for $\mathrm{H} 3$ indicate that historical sales volatility is apparently a strong predictor of flexibility in management's resource procurement planning.

\subsubsection{Hypothesis H4: Industry effects}

Under hypothesis H4, we predict that the coefficients on the deviations from industry mean values for average historical sales growth and for the market-to-book ratio would be negative, and the coefficient on the deviation from industry mean for sales volatility would be positive.

Table 4 provides the results for our test of $\mathrm{H} 4$. The coefficients on the deviation from industry historical growth $(-0.3151$ in column I and -0.2811 in column III) and the deviation from industry market-to-book ratio $(-0.0379$ in column II and -0.0337 in column III) are significantly negative at the $1 \%$ level. The coefficients on the deviation from industry sales volatility $(0.2217$ in column I, 0.2156 in column II, and 0.2454 in column III) are significantly positive at the $1 \%$ level. Thus, we find evidence consistent with firms developing firm-specific resource procurement plans that lend themselves to firm-specific differences in demand uncertainty.

\subsection{Additional analysis investigating asymmetric cost responsiveness}

Asymmetric cost responsiveness is conditioned on the information available to the manager about the permanence of a decline in sales. Because the manager obtains more information about the likelihood of demand recovery with the passage of time, extending the SG\&A costs and sales change period (from 1 year to 2 or more years) leads to lower observed asymmetric cost responsiveness, i.e., the estimated coefficient $\beta_{2}$ in the basic model is lower (Anderson et al., 2003). Our hypotheses relate to demand factors that influence the selection of a long-term resource procurement plan (flexible versus committed). Therefore, while we anticipate some erosion in the estimated coefficients on the growth and volatility variables as the observation window is extended, we expect that the observed relations will be reasonably robust to this extension. We repeated tests of our first three hypotheses by estimating our empirical model using 2- and 4-year change windows for SG\&A costs and sales. Panels A (2-year changes) and B (4-year changes) of Table 5 provide the results of our estimations. Comparing column I (estimation of the basic model) for panels $A$ and $B$, we find estimates of $\beta_{2}$ decline from -0.1115 for the two-period aggregation model to -0.064 for the four-period aggregation model, consistent with previous literature (Anderson et al., 2003). The results presented in the remaining columns support our first three hypotheses. The coefficients on the average historical growth variable (column II and IV of panels A and B) diminish somewhat with the length of the observation window but are significantly negative in both panels, consistent with the long-term nature of many committed resources. The coefficients

Table 3

Precedent and antecedent information and cost responsiveness

\begin{tabular}{|c|c|c|c|c|c|c|c|}
\hline $\log \left[\frac{\mathrm{SGA}_{i, t}}{\mathrm{SGA}_{i, t-1}}\right]=\beta_{0}+\beta_{1} \log$ & $\left.\frac{\operatorname{Sales}_{i, t}}{\operatorname{Sales}_{i, t-1}}\right]+\beta_{2} \times D_{i, t} \times \log [$ & $\left.\frac{\text { Sales }_{i, t}}{\operatorname{Sales}_{i, t-1}}\right]+\beta$ & $\mathrm{th}_{i, t-1} \times D_{i, t} \times \log$ & $\left.\frac{\operatorname{Sales}_{i, t}}{\operatorname{Sales}_{i, t-1}}\right]+\beta$ & $\operatorname{lity}_{i, t-1} \times D_{i, t} \times \log$ & {$\left[\frac{\text { Sales }_{i, t}}{\operatorname{Sales}_{i, t-1}}\right]+$} & \\
\hline \multirow[t]{2}{*}{ Column } & \multirow[b]{2}{*}{$\begin{array}{l}\text { Predicted } \\
\text { sign }\end{array}$} & \multicolumn{2}{|l|}{ I } & \multicolumn{2}{|l|}{ II } & \multicolumn{2}{|l|}{ III } \\
\hline & & $\begin{array}{l}\text { Coefficient } \\
\text { estimate }\end{array}$ & $T$-stat & $\begin{array}{l}\text { Coefficient } \\
\text { estimate }\end{array}$ & $T$-stat & $\begin{array}{l}\text { Coefficient } \\
\text { estimate }\end{array}$ & T-stat \\
\hline Intercept & & $0.0256^{* * *}$ & 31.81 & $0.0253^{* * *}$ & 31.55 & $0.0257^{\text {*** }}$ & 32.11 \\
\hline $\log \left(\right.$ Sale $_{i, t} /$ Sale $\left._{i, t-1}\right)$ & + & $0.6453^{* * *}$ & 110.17 & $0.6464^{* * *}$ & 110.48 & $0.6450^{* * *}$ & 110.23 \\
\hline$D_{i, t} x \log \left(\right.$ Sale $_{i, t} /$ Sale $\left._{i, t-1}\right)$ & - & $-0.2046^{* * *}$ & -13.22 & $-0.1956^{* * *}$ & -12.78 & $-0.1558^{\text {*** }}$ & -9.85 \\
\hline Historical growth & - & $-0.3736^{* * *}$ & -12.18 & & & $-0.3318^{* * *}$ & -10.55 \\
\hline MTB & - & & & $-0.0408^{* * *}$ & -12.07 & $-0.0365^{\text {*** }}$ & -10.66 \\
\hline Volatility & + & $0.2571^{* * *}$ & 9.50 & $0.2573^{* * *}$ & 10.48 & $0.2858^{\text {*** }}$ & 11.40 \\
\hline$R$-Squared & & 0.4270 & & 0.4276 & & 0.4305 & \\
\hline$N$ & & 79,177 & & & & & \\
\hline
\end{tabular}

t-Statistics are calculated after adjusting the standard errors for heteroskedasticity, serial, and cross-sectional correlation using a two-way cluster at the firm and year level.

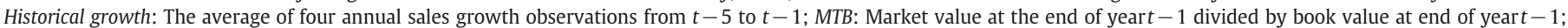
Volatility: The standard deviation of sales revenue (divided by total assets) for the years $t-5$ to $t-1$.

$* * * \quad p<0.01$. 
Table 4

Precedent and antecedent information, cost responsiveness and industry benchmarks.

\begin{tabular}{|c|c|c|c|c|c|c|c|}
\hline \multirow[t]{2}{*}{ Column } & \multirow[b]{2}{*}{$\begin{array}{l}\text { Predicted } \\
\text { sign }\end{array}$} & \multicolumn{2}{|l|}{ I } & \multicolumn{2}{|l|}{ II } & \multicolumn{2}{|l|}{ III } \\
\hline & & $\begin{array}{l}\text { Coefficient } \\
\text { estimate }\end{array}$ & $T$-stat & $\begin{array}{l}\text { Coefficient } \\
\text { estimate }\end{array}$ & T-stat & $\begin{array}{l}\text { Coefficient } \\
\text { estimate }\end{array}$ & T-stat \\
\hline Intercept & & $0.0261^{* * * *}$ & 32.46 & $0.0255^{* * *}$ & 31.91 & $0.0263^{* * *}$ & 32.94 \\
\hline$D_{i, t} x \log \left(\right.$ Sale $_{i, t} /$ Sale $\left._{i, t-1}\right)$ & - & $-0.1607^{* * *}$ & -6.20 & $-0.2254^{* * *}$ & -9.04 & $-0.0940^{* * *}$ & -3.42 \\
\hline Historical growth Industry & - & $-1.0431^{* * *}$ & -10.79 & & & $-0.8922^{* * * *}$ & -9.18 \\
\hline Historical growth deviation & - & $-0.3151^{* * *}$ & -8.72 & & & $-0.2811^{* * *}$ & -8.17 \\
\hline MTB industry & - & & & $-0.0630^{* * *}$ & -8.97 & $-0.0490^{* * *}$ & -6.69 \\
\hline Volatility deviation & + & $0.2217^{* * *}$ & 7.31 & $0.2156^{* * *}$ & 7.65 & $0.2454^{* * *}$ & 8.82 \\
\hline$R$-Squared & & 0.4292 & & 0.4284 & & 0.4327 & \\
\hline$N$ & & 79,177 & & & & & \\
\hline
\end{tabular}

$t$-Statistics are calculated after adjusting the standard errors for heteroskedasticity, serial, and cross-sectional correlation.

Historical growth industry: Average of Historical Growth in a firm's two-digit SIC code industry (firms that are in a two-digit SIC code containing fewer than four members are classified as "Other"); Historical growth deviation: Difference between Historical Growth and Historical Growth Industry; MTB Industry: Average of MTB in a firm's two-digit SIC code industry; MTB Deviation: Difference between MTB and MTB Industry; Volatility Industry: Average of Volatility in a firm's two-digit SIC code industry; Volatility Deviation: Difference between Volatility and Volatility Industry.

$* * * \quad p<0.01$.

on the historical volatility variable (columns II, III and IV) are significantly negative and strikingly similar across the two panels, consistent with greater use of flexible resources reducing asymmetric cost responsiveness. The coefficients on the market-to-book ratio (columns III and IV) are significantly negative and hold up well across the panels, consistent with forward-looking investment in committed resources.

Our analysis treats growth and volatility as two dimensions of demand uncertainty that separately influence managers' procurement decisions. Because there may be some interaction between growth and volatility in setting expectations with regard to demand uncertainty, we also estimate our models with interaction terms for growth and volatility. We present the results of these estimations in Table 6. Column I reports results with historical growth interacted with historical volatility. The coefficient on the interaction term is significantly positive and the results on the main variables of interest are robust to this specification. Column II reports results with the market-to-book ratio interacted with historical volatility. The coefficient on the interaction term is not significantly different from zero and the results on the main variables of interest are also robust to this specification. Column III includes both growth variables and corresponding interaction terms. In this case, both coefficients on the interaction terms are significantly different from zero and the results on the main variables of interest are all robust to this specification.

Our tests so far have used cross-sectional panel data to evaluate how resource decision making across companies is influenced by information about demand uncertainty. It is also interesting to analyze decision making on a company-by-company basis. Therefore, we further examine the association between the conditioning variables and asymmetry in the response of SG\&A cost changes to sales declines using a time-series analysis. We first estimate the basic model on a firm-by-firm basis over four 15-year periods (1980-1994, 1985-1999, 1990-2004 and 1995-2009) for firms with at least 10 observations and three sales decline observations in a given 15-year period. Panel A

Table 5

Precedent and antecedent information and cost responsiveness with longer change periods.

\begin{tabular}{|c|c|c|c|c|c|c|c|c|c|}
\hline \multirow[t]{2}{*}{ Column } & \multirow[b]{2}{*}{$\begin{array}{l}\text { Predicted } \\
\text { sign }\end{array}$} & \multicolumn{2}{|l|}{ I } & \multicolumn{2}{|l|}{ II } & \multicolumn{2}{|l|}{ III } & \multicolumn{2}{|l|}{ IV } \\
\hline & & $\begin{array}{l}\text { Coefficient } \\
\text { estimate }\end{array}$ & $T$-stat & $\begin{array}{l}\text { Coefficient } \\
\text { estimate }\end{array}$ & T-stat & $\begin{array}{l}\text { Coefficient } \\
\text { estimate }\end{array}$ & $T$-stat & $\begin{array}{l}\text { Coefficient } \\
\text { estimate }\end{array}$ & $T$-stat \\
\hline \multicolumn{10}{|l|}{ Panel A: 2-year periods } \\
\hline Intercept & & $0.0501^{* * *}$ & 28.65 & $0.0476^{* * *}$ & 28.84 & $0.0495^{* * *}$ & 28.40 & $0.0478^{* * *}$ & 28.95 \\
\hline $\log \left(\right.$ Sale $_{i, t} /$ Sale $\left._{i, t-1}\right)$ & + & $0.6958^{* * *}$ & 99.24 & $0.6957^{* * *}$ & 102.10 & $0.6968^{* * *}$ & 99.35 & $0.6956^{* * *}$ & 102.12 \\
\hline$D_{i, t} x \log \left(\right.$ Sale $_{i, t} /$ Sale $\left._{i, t-1}\right)$ & - & $-0.1115^{* * *}$ & -6.89 & $-0.1184^{* * *}$ & -5.51 & $-0.0898^{* * *}$ & -3.80 & $-0.0696^{\text {*** }}$ & -3.17 \\
\hline Historical growth & - & & & $-0.4695^{* * *}$ & -7.93 & & & $-0.4005^{* * *}$ & -7.34 \\
\hline MTB & - & & & & & $-0.0450^{* * *}$ & -7.22 & $-0.0358^{* * *}$ & -6.73 \\
\hline Volatility & + & & & $0.2345^{* * *}$ & 5.73 & $0.1931^{* * *}$ & 4.43 & $0.2630^{* * *}$ & 6.55 \\
\hline$R$-Squared & & 0.5268 & & 0.5299 & & 0.5303 & & 0.5318 & \\
\hline$N$ & & 33,004 & & & & & & & \\
\hline \multicolumn{10}{|l|}{ Panel B: 4-year periods } \\
\hline Intercept & & $0.0751^{* * *}$ & 18.28 & $0.0772^{* * *}$ & 21.48 & $0.0740^{* * *}$ & 18.01 & $0.0766^{* * *}$ & 21.30 \\
\hline $\log \left(\right.$ Sale $_{\mathrm{i}, t} /$ Sale $\left._{i, t-1}\right)$ & + & $0.7590^{* * *}$ & 79.56 & $0.7517^{* * *}$ & 85.79 & $0.7605^{* * * *}$ & 79.66 & $0.7525^{* * *}$ & 85.84 \\
\hline$D_{i, t} x \log \left(\right.$ Sale $_{i, t} /$ Sale $\left._{i, t-1}\right)$ & - & $-0.0638^{* *}$ & -2.56 & $-0.0734^{* *}$ & -2.53 & $-0.0494^{* * *}$ & -1.41 & $-0.0172^{* * *}$ & -0.53 \\
\hline Historical growth & - & & & $-0.3179^{* * *}$ & -3.50 & & & $-0.2699^{* * *}$ & -2.88 \\
\hline MTB & - & & & & & $-0.0473^{* * *}$ & -4.66 & $-0.0413^{* * *}$ & -4.56 \\
\hline Volatility & + & & & $0.2141^{* *}$ & 2.79 & $0.1873^{* * *}$ & 2.70 & $0.2398^{* * *}$ & 3.41 \\
\hline$R$-Squared & & 0.6275 & & 0.6285 & & 0.6290 & & 0.6297 & \\
\hline$N$ & & 11,832 & & & & & & & \\
\hline
\end{tabular}

$t$-Statistics are calculated after adjusting the standard errors for heteroskedasticity, serial, and cross-sectional correlation using a two-way cluster at the firm and year level. $* * * \quad p<0.01$

$* * \quad p<0.05$. 
Table 6

Precedent and antecedent information and cost responsiveness with growth and volatility interactions

$$
\begin{aligned}
\log \left[\frac{\mathrm{SGA}_{i, t}}{\mathrm{SGA}_{i, t}}\right]= & \left.\beta_{0}+\beta_{1} \log \left[\frac{\text { Sales }_{i, t}}{\text { Sales }_{i, t}}\right]+\beta_{2} \times D_{i, t} \times \log \left[\frac{\text { Sales }_{i, t}}{\text { Sales }_{i, t-1}}\right]+\beta_{3} \times \text { Growth }_{i, t-1} \times D_{i, t} \times \log \left[\frac{\text { Sales }_{i, t}}{\text { Sales }_{i, t-1}}\right]+\beta_{4} \times \text { Volatility }_{i, t-1} \times D_{i, t} \times \log _{\left.\frac{\text { Sales }_{i, t}}{\text { Sales }_{i, t-1}}\right]}\right] \\
& +\beta_{5} \times \text { Growth }_{i, t-1} \times \text { Volatility }_{i, t-1} \times D_{i, t} \times \log \left[\frac{\text { Sales }_{i, t}}{\text { Sales }_{i, t-1}}\right]+\varepsilon_{i, t} .
\end{aligned}
$$

\begin{tabular}{|c|c|c|c|c|c|c|c|}
\hline \multirow[t]{2}{*}{ Column } & \multirow[b]{2}{*}{$\begin{array}{l}\text { Predicted } \\
\text { sign }\end{array}$} & \multicolumn{2}{|l|}{ I } & \multicolumn{2}{|l|}{ II } & \multicolumn{2}{|l|}{ III } \\
\hline & & $\begin{array}{l}\text { Coefficient } \\
\text { estimate }\end{array}$ & $T$-stat & $\begin{array}{l}\text { Coefficient } \\
\text { estimate }\end{array}$ & T-stat & $\begin{array}{l}\text { Coefficient } \\
\text { estimate }\end{array}$ & T-stat \\
\hline Intercept & & $0.0257^{* * *}$ & 31.50 & $0.0253^{* * *}$ & 31.53 & $0.0259^{* * *}$ & 32.22 \\
\hline $\log \left(\right.$ Sale $_{i, t} /$ Sale $\left._{i, t-1}\right)$ & + & $0.6462^{* * *}$ & 110.11 & $0.6465^{* * *}$ & 110.48 & $0.6446^{* * *}$ & 110.12 \\
\hline$D_{i, t} x \log \left(\right.$ Sale $_{i, t} /$ Sale $\left._{i, t-1}\right)$ & - & $-0.1759^{* * *}$ & -10.75 & $-0.2034^{* * *}$ & -11.77 & $-0.1337^{* * *}$ & -7.33 \\
\hline Historical growth & - & $-0.6194^{* * *}$ & -12.02 & & & $-0.5856^{* * *}$ & -11.56 \\
\hline MTB & - & & & $-0.0371^{* * *}$ & -6.72 & $-0.0282^{* * *}$ & -5.21 \\
\hline Volatility & + & $0.1721^{* * *}$ & 5.89 & $0.2746^{\text {*** }}$ & 9.44 & $0.2365^{* * *}$ & 7.70 \\
\hline Historical Growth $\times$ Volatility & & $0.4837^{* * *}$ & 5.37 & & & $0.5034^{* * *}$ & 5.82 \\
\hline MTB $\times$ Volatility & & & & $-0.0073^{* * *}$ & -0.92 & $-0.0160^{* *}$ & -2.04 \\
\hline$R$-Squared & & 0.4280 & & 0.4276 & & 0.4316 & \\
\hline$N$ & & 79,177 & & & & & \\
\hline
\end{tabular}

$t$-Statistics are calculated after adjusting the standard errors for heteroskedasticity, serial, and cross-sectional correlation using a two-way cluster at the firm and year level.

*** $p<0.01$.

** $p<0.05$.

of Table 7 presents the aggregate results of our estimations. The results are consistent with our cross-sectional estimates evidenced by average estimates of $\beta_{1}$ of 0.7285 and $\beta_{2}$ of -0.2582 .

Next, we regress $\beta_{2}$ for each firm and 15 -year period combination on our conditioning variables. We also include industry dummies in the regression, although we do not tabulate them. Panel B of Table 7 presents the results of this estimation. The estimated coefficient on historical growth is $-0.1256(t=-1.90)$, on market-to-book is -0.0116 $(t=-2.26)$, and on historical sales volatility is $0.1374(t=-2.07)$.

Table 7

Precedent and antecedent information and cost responsiveness: time series analysis.

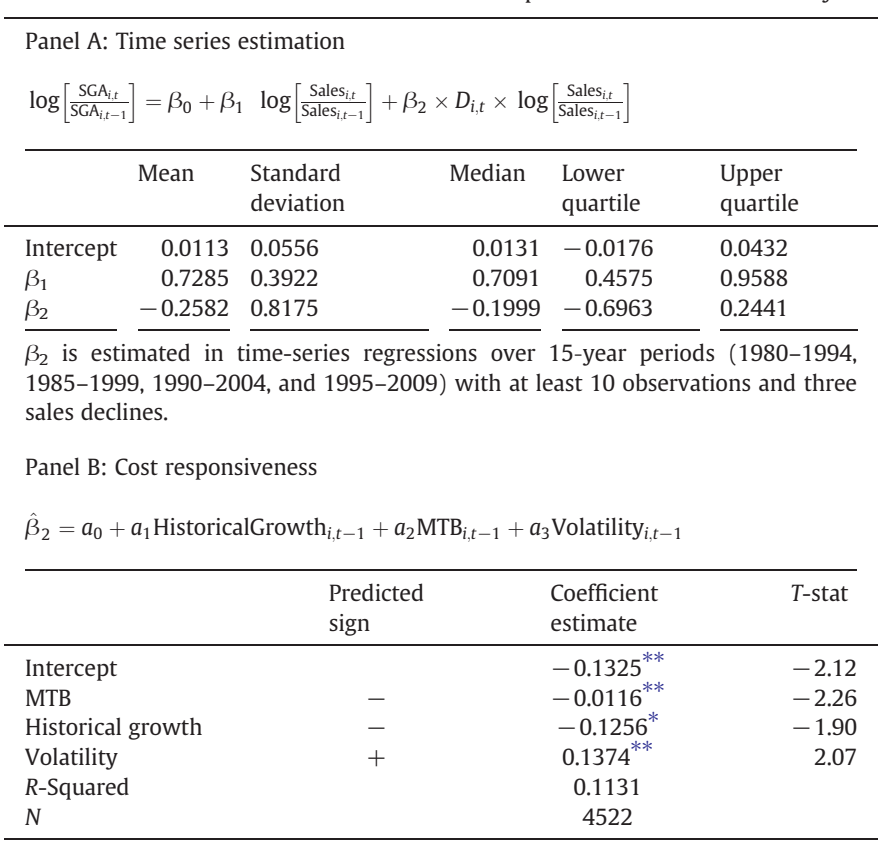

Estimated $\beta_{2}$ is regressed on Historical Growth, MTB and Volatility. Independent variables are measured at the beginning of each time period. Industry dummies are included in the regression but not included in the table.

$* * \quad p<0.05$.

$* p<0.10$.
These results further support our first three hypotheses, indicating that the influence of the precedent and antecedent variables is persistent over time.

\section{Conclusion}

Managing and controlling costs in relation to production and sales is critical to company success. Developing a cost management strategy requires the selection and support of a resource procurement plan. While such a plan is multifaceted and complex, it manifests itself in measurable cross-sectional differences in cost behavior. Traditional cost management approaches described in managerial accounting textbooks consider how the mix of fixed versus variable costs affects the degree of operating leverage. Treatments in financial analysis textbooks evaluate costs as a percentage of revenues. These approaches fail to consider how different resource procurement choices affect cost asymmetry (Anderson et al., 2003, 2007) that reduces margins when sales decline. We contrast a cost management strategy focusing on cost agility based on flexible resources to a cost management strategy focusing on cost advantages derived from committed resources. While a strategy focusing on agility reduces asymmetry in cost behavior, it leads to higher unit costs for resources and loss of control over resources. A strategy focusing on committed resources leads to greater cost asymmetry but may provide competitive advantages due to lower unit costs and greater control over resources.

Observed asymmetric cost responsiveness reflects decisions that companies have made over time with respect to using flexible versus committed resources. Experience and expectations about demand uncertainty and about the costs of using flexible or committed resources influence resource decision making and lead to the formulation, either deliberately or instinctively, of a resource procurement plan. Our analysis looks at asymmetric cost responsiveness as an outcome of the research procurement plans that companies have developed over time. Thus, we draw on the collective experience of a large number of companies to provide information about how managers might combine precedent and antecedent information to formulate a resource procurement plan as a means of strategic cost management. Our findings are consistent with managers making procurement decisions that trade off flexibility and commitment based on their experience and expectations. 


\section{References}

Anderson, M. C., Banker, R. D., Huang, R., \& Janakiraman, S. N. (2007). Cost behavior and fundamental analysis of SG\&A costs. Journal of Accounting, Auditing \& Finance, 22(1), 1-28

Anderson, M. C., Banker, R. D., \& Janakiraman, S. N. (2003). Are selling, general, and administrative costs 'sticky'? Journal of Accounting Research, 41(1), 47-63.

Baber, W. R., Kim, J. D., \& Kumar, K. R. (1999). On the use of intra-industry information to improve earnings forecasts. Journal of Business Finance and Accounting, 26(9-10), 1177-1198.

Banker, R. D., Byzalov, D., Ciftci, M., \& Mashruwala, R. (2012). Managerial optimism and cost behavior. Temple University Working Paper.

Banker, R. D., Huang, R., \& Natarajan, R. (2011). Equity incentives and long-term value created by SG\&A expenditure. Contemporary Accounting Research, 28(3), 794-830.

Belsley, D. A., Kuh, E., \& Welsch, R. E. (1980). Regression diagnostics: identifying influential data and sources of collinearity. : John Wiley \& Sons.

Daniel, F., Lohrke, F. T., Fornaciari, C. J., \& Turner, R. A., Jr. (2004). Slack resources and firm performance: a meta-analysis. Journal of Business Research, 57(6), 565-574.

DeRijcke, J., Faes, W., \& Vollering, J. (1985). Strategy formulation and implementation during purchasing of production materials. Journal of Business Research, 13(1), 19-33.

Dunn, K. A., Kohlbeck, M. J., \& Magilke, M. J. (2009). Future profitability, operating cash flows, and market valuations associated with offshoring arrangements of technology jobs. Journal of Information Systems, 23(2), 25-47.

Fairfield, P. M., Ramnath, S., \& Yohn, T. L. (2009). Do industry-level analyses improve forecasts of financial performance? Journal of Accounting Research, 47(1), 147-178.
Finney, R. Z., Campbell, N. D., \& Powell, C. M. (2005). Strategies and resources: pathways to success? Journal of Business Research, 58(12), 1721-1729.

Hooley, G. J., Greenley, G. E., Cadogan, J. W., \& Fahy, J. (2005). The performance impact of marketing resources. Journal of Business Research, 58(1), 18-27.

Kaya, M., \& Özer, Ö. (2009). Quality risk in outsourcing: noncontractible product quality and private quality cost information. Naval Research Logistics, 56(7), 669-685.

Lev, B. (1969). Industry averages as targets for financial ratios. Journal of Accounting Research, 7(2), 290-299.

McGee, R. W. (2005). Outsourcing: an ethical analysis of an international trade issue. Florida International University Working paper.

Neelankavila, J. P., \& Alaganar, V. T. (2003). Strategic resource commitment of high-technology firms: an international comparison. Journal of Business Research, 56(6), 493-502

Petersen, M. (2009). Estimating standard errors in finance panel data sets: comparing approaches. The Review of Financial Studies, 22(1), 435-480.

Pinker, E. J., \& Larson, R. C. (2003). Optimizing the use of contingent labor when demand is uncertain. European Journal of Operational Research, 144(1), 39-55.

Rebitzer, J. B., \& Taylor, L. J. (1991). A model of dual labor markets when product demand is uncertain. Quarterly Journal of Economics, 106(4), 1373-1383.

Ren, Z. J., \& Zhang, F. (2009). Service outsourcing: capacity, quality and correlated costs. Washington University Working paper.

Ren, Z. J., \& Zhou, Y. P. (2008). Call center outsourcing: coordinating staffing level and service quality. Management Science, 54(2), 369-383.

Subramaniam, C., \& Weidenmier, M. L. (2003). Additional evidence on the sticky behavior of costs. Texas Christian University Working paper. 